\title{
PRESSUPOSTOS FREIREANOS, CTS E PLACTS NO ENSINO DE CIÊNCIAS: APROXIMAÇÕES E DISTANCIAMENTOS
}

\author{
FREIREAN ASSUMPTIONS, STS AND LATSTS IN SCIENCE TEACHING: \\ APPROACHES AND DISTANCES
}
SUPOSICIONES FREIREANAS, CTS Y PLACTS EN LA ENSEÑANZA DE CIENCIAS: APROXIMACIONES Y DISTANCIAMIENTOS

$\begin{array}{r}\text { Guilherme Schwan }^{1^{*}} \text { (D) } \\ \text { Rosemar Ayres dos Santos } \\ \hline\end{array}$

\section{RESUMO}

Aproximações entre o educador Paulo Freire e referenciais ligados ao enfoque Ciência-TecnologiaSociedade (CTS) começam a tomar maiores contornos, principalmente no Ensino de Ciências (EC). Este trabalho apresenta uma revisão bibliográfica de cunho qualitativo, através do repositório do Instituto Brasileiro de Informação em Ciência e Tecnologia (IBICT), no qual investigamos: de que maneira a articulação entre os pressupostos de Paulo Freire do enfoque (CTS) e o Pensamento LatinoAmericano em Ciência-Tecnologia-Sociedade (PLACTS) estão sendo desenvolvidos, principalmente, no EC? Com o objetivo de discutir sinalizações e reflexões acerca de pesquisas que utilizam aproximações Freire/CTS na Educação, ligadas ao EC. Como método de análise do corpus, seguimos com a Análise Textual Discursiva. Seus resultados estão apresentados em quatro categorias: i) Diálogos na estruturação curricular sob aproximação Freire-CTS. ii) Busca da participação e democratização em processos decisórios diante de temas Científico-Tecnológicos. iii) Encontro com a educação problematizadora de Freire e a suposta neutralidade da Ciência-Tecnologia iiii) Divergências e desafios entre abordagens Freire-CTS. Portanto, entendemos que a referida aproximação aponta para mudanças, principalmente no EC, ao problematizar questões sociais, contribuindo na formação crítica dos sujeitos diante sua realidade.

Palavras-chave: Paulo Freire. CTS/PLACTS. Ensino de Ciências. Currículo.

\begin{abstract}
Approaches between the educator Paulo Freire and references connected to the focus of ScienceTechnology-Society (STS) starts to take on greater outline, mainly, in Science Teaching (ST). This work presents a qualitative bibliographic review, throughout the repository of the Brazilian Institute of Information in Science and Technology (IBICT/BIIST), in which we investigated: how the joint between Paulo Freire's assumptions and the focus (STS) and Latin American Thought in Science,

\footnotetext{
${ }^{1^{*}}$ Mestre em Ensino de Ciências pela Universidade Federal da Fronteira Sul (UFFS). Docente na rede pública municipal do município de Santo Ângelo, Rio Grande do Sul, Brasil. Endereço para correspondência: Rua/Av. Independência, 931, AP. 101, Centro, Salvador das Missões, Rio Grande do Sul, Brasil, CEP: 97940 - 000. Email: guilhermeschwan@gmail.com.

$2^{* *}$ Doutora em Educação pela Universidade Federal de Santa Maria (UFSM). Docente do Programa de PósGraduação em Ensino de Ciências (PPGEC) da Universidade Federal da Fronteira Sul (UFFS), Cerro Largo, Rio Grande do Sul, Brasil. Endereço para correspondência: Rua/Av Jacob Reinaldo Haupenthal, 1580, São Pedro, Cerro Largo, Rio Grande do Sul, Brasil, CEP: 97900-000. E-mail: roseayres07@gmail.com.
} 
Technology and Society (LAT-STS) are being developed, mostly, on ST? With the aim to discuss the signaling and thinking about the researches that uses Freire's STS approaches in Education, connected to ST. As corpus analysis method we continue with Discursive Textual Analysis. Its results are presented in four categories: i) Dialogues in curriculum structuring under Freire-STS approach. ii) The search for participation and democratization in decision-making processes regarding ScientificTechnological themes. iii) A meeting with Freire's problematizing education and the supposed neutrality of Science-Technology. iiii) Divergences and challenges between Freire-STS approaches. However, we understand that the referred approach points to changes, mostly on ST, when problematizing social points, contributing to the critical formation of subjects before their reality.

Keywords: Paulo Freire. STS/LATSTS. Science Teaching. Curriculum.

\section{RESUMEN}

Aproximación entre el educador Paulo Freire y referencias vinculadas al enfoque Ciencia-TecnologíaSociedad (CTS), empiezan a tomar mayores contornos, principalmente, en la Enseñanza de las Ciencias (EC). Este trabajo presenta una revisión bibliográfica cualitativa, a través del repositorio del Instituto Brasileño de Información en Ciência y Tecnología (IBICT), en la que investigamos: de que manera se está desarollando la articulación entre los supuestos de Paulo Freire del enfoque (CTS) y Pensamento Latino-Americano em Ciência-Tecnologia-Sociedade (PLACTS) principalmente en la EC? Con el objetivo de discutir señalizaciónes y reflexiones sobre investigaciones que utilizan aproximaciones Freire/CTS en la educación, vinculadas a EC. Como método de análisis del corpus, continuamos con el Análisis Textual Discursivo. Sus resultados se presentan en cuatro categorías: i) Diálogos en la estructuración curricular bajo la aproximación Freire-CTS. ii) Busqueda de participación e democratización en los procesos de toma de decisiones frente a las temáticas Científico-Tecnológicas. iii) Encuentro con la educación problematizadora de Freire y la supuesta neutralidad de la Ciencia-Tecnología iiii) Divergencias y retos entre enfoques Freire-CTS. Por lo tanto, entendemos que el referido enfoque apunta a cambios, principalmente en la EC, al problematizar los temas sociales, contribuyendo a la formación crítica de los sujetos frente a su realidad.

Palabras clave: Paulo Freire. CTS/PLACTS. Enseñanza de Ciencias. Currículo.

\section{1 À GUISA DE UMA ENUNCIAÇÃO}

A Educação em Ciências, envolta por configurações curriculares com perspectiva de produção de conhecimentos escolares mais significativos aos estudantes, vem recebendo transformações ao longo do tempo. Nesse sentido, práticas significativas ao seu contexto podem contribuir com maior participação, consequentemente, julgamentos conscientes e críticos de problemáticas visando à intervenção na tomada de decisões, objetivo de uma real participação democrática.

Os pressupostos educacionais de Freire (2020b) apontam para maior participação em processos decisórios, partindo da crença do "homem como um ser inconcluso" (p. 101), 
imerso em uma realidade de mesma forma incompleta, porém, "em seu permanente movimento de busca do ser mais" (p. 101), ou seja, na sua busca por emancipação enquanto sujeito capaz de transformar a realidade histórica, superando a condição de "objetos ao invés de sujeitos históricos" (AULER, 2007, p. 176). Condição de objeto, estabelecida pela base de estrutura opressora diante dos oprimidos ${ }^{3}$, impedindo o desenvolvimento crítico e transformador do mundo desta última classe. Com o propósito de inverter esta lógica, Freire defende um processo de ensino e aprendizagem na superação de uma concepção bancária, na qual educadores realizam depósitos em estudantes, o que se constitui a base da alienação cultura do silêncio, transpondo esta, em direção a uma educação problematizadora, essencialmente dialógica.

Paulo Freire é um pensador e educador brasileiro, o qual centrou seu trabalho, principalmente, na educação popular, almejando a alfabetização em adultos, em contextos educativos não formais. Nesse caso, a alfabetização se deu a partir do que Freire (2020b) denominou de palavra geradora, ou seja, "partiu-se de uma palavra pertencente à realidade desses educandos, não ensinando apenas a escrita dessa palavra, mas problematizando-a em sua dimensão social" (SANTOS, 2016, p. 63). Mesmo que na proposta original de Freire não existam preocupações diretas com questões curriculares, sua prática é fundamentada na organização curricular mediante temas geradores através da investigação temática, o que remete ao campo curricular, sendo esta uma proposta fundamentada na dialogicidade como essência da educação como prática da liberdade (FREIRE, 2020b, p. 107). Na perspectiva freireana, o diálogo é realizado com o educando e não sobre ele, muito menos dialogando sobre qualquer assunto: professor e estudante constroem uma relação dialógica a partir da problematização de sua realidade com vistas à formação crítica do educando.

Freire, em suas experiências com educação popular, para construir um mundo mais justo e solidário, trabalha dimensões inéditas como a Investigação Temática, em configurações curriculares na busca de Tema gerador, porém não se dedica a aprofundamentos no campo da Ciência-Tecnologia (CT). Essa constitui foco de estudo do Pensamento Latino-Americano em Ciência-Tecnologia-Sociedade (PLACTS), o qual, por sua

\footnotetext{
${ }^{3}$ Oprimido e Opressor categorias freireanas que: "Son los polos opuestos de las relaciones sociales de antagonismo. Fundamentalmente, oprimidos y opresores son clases sociales antagónicas y en lucha. Sin embargo, es posible que se instauren relaciones de opresión entre los propios oprimidos. Como seres involucrados en la relación de dominación, tanto oprimidos como opresores tienen su vocación ontológica negada por la realidad histórica de opresión que funda sus existencias. Solo la praxis liberadora del oprimido es capaz de superar la opresión y restaurar la humanidad de ambos" (STRECK; REDIN; ZITKOSKI, 2015, p. 369). 
vez, se encontra afastado do campo educacional (AULER, 2018). É nesse ponto que se situa a originalidade da proposta de Auler (2007, 2018), ao estabelecer a articulação: enquanto PLACTS traz aprofundamentos da CT, Freire atua em aspectos educacionais.

Nesse sentido, investigamos: de que maneira a articulação entre os pressupostos de Freire e o enfoque Ciência-Tecnologia-Sociedade (CTS) estão sendo desenvolvidos no Ensino de Ciências? Objetiva-se apresentar sinalizações/reflexões acerca de pesquisas que utilizam aproximações Freire-CTS na Educação em Ciências (EC). A decorrente pesquisa surge da necessidade de contribuir ao aporte teórico de um estudo de maior abrangência - Dissertação, aprofundando olhares a referenciais que cercam a dinâmica curricular pela perspectiva do enfoque CTS - PLACTS e dos pressupostos freireanos.

Este trabalho está organizado em 6 tópicos. O tópico 2 trata do referencial teórico que dá sustentação à pesquisa, utilizando diversas obras de autores ligados ao objetivo do trabalho. O tópico 3 destaca a metodologia utilizada na busca de pesquisas que compõem o corpus de análise. No tópico 4 são abordados os resultados, apresentados em 4 categorias. $\mathrm{O}$ tópico 5 é composto pelas conclusões alcançadas e, no último tópico, de número 6 , apresentamos as referências utilizadas ao longo do trabalho.

\section{ARTICULAÇÃO ENTRE FREIRE E O PLACTS: PRÁXIS ASSENTAdA NO CONTEXTO LATINO-AMERICANO}

O movimento CTS teve origem em meados do século XX, no Hemisfério Norte, principalmente nos países ditos desenvolvidos, com o intuito do desenvolvimento do bemestar social, contrapondo-se à ideia mítica de que mais Ciência e mais Tecnologia irão, necessariamente, resolver os problemas ambientais, sociais e econômicos. Assim, esse movimento tem como objetivo central a busca da democratização de processos decisórios envolvendo temas/problemas condicionados pelo desenvolvimento da CT "na sociedade, dos produtos científico-tecnológicos, ou seja, busca-se uma participação que atenue seus efeitos negativos, indesejáveis" (SANTOS; ROSA; AULER, 2013, p. 18).

Nesse mesmo período, surge na América Latina o PLACTS, buscando a produção de CT nacional que atendesse às demandas locais, tendo em vista que a importada de países ditos desenvolvidos “[...] não necessariamente seria adequada aos interesses e necessidades da 
população latino-americana, sendo, para eles, necessária uma reorientação da agenda de pesquisa em CT" (ROSO; AULER, 2016, p. 372).

Numa crítica à linearidade em que a CT era transmitida pelos países denominados desenvolvidos, vale destacar que o fortalecimento inicial do PLACTS se deu pela necessidade advinda do processo de industrialização dos países latino-americanos, valorizando e incentivando a CT produzida por pesquisadores destes países, (inicialmente Brasil e Argentina), em substituição à importação de tecnologias, as quais causavam grande dependência dos países do Hemisfério Norte. Estabelecendo-se como uma nova Política de Ciência e Tecnologia (PCT), o que levou a se difundir em meio acadêmico e, sendo uma política que agradava o Estado militar-autoritário, "bastante coerente com o papel de liderança que o país nela pretendia assumir” (DAGNINO, 2013, p. 40).

Fatos que contribuíram para o fortalecimento do PLACTS que busca uma reorientação da PCT regional, coerente com as demandas vivenciadas pelos países latino-americanos. Contemporaneamente, Renato Dagnino vem sendo destaque em pesquisas sobre o PLACTS e sua crítica de PCT inspirada em países de primeiro mundo desconsiderando as demandas locais. Dagnino (2008) defende uma reorientação da atividade científico-tecnológica, uma política que se oriente pelas demandas das necessidades dos países da América Latina, não a forças ligadas a interesses econômicos de empresas privadas que acabam definindo a PCT e, por sua vez, determinando a agenda de pesquisa, carregada de valores consumistas.

Considerando a CT como uma construção social e historicamente determinada, um processo de diferentes interesses, que, dependendo da capacidade de diferentes atores sociais interferir no processo de decisão, pode introduzir na PCT demandas e interesses relativos a outros segmentos da sociedade, diferentes das baseadas em valores industriais, supostamente neutras (DAGNINO, 2008).

O PLACTS (DAGNINO, 2006) não repercutiu inicialmente no âmbito educacional, como o movimento CTS, porém, contemporaneamente, alguns educadores brasileiros, como Auler (2007, 2018), Auler e Delizoicov (2015), Santos (2016, 2019), Strieder (2012), estão desenvolvendo pesquisas ligadas à Educação neste viés, construindo aproximações de referências ligados ao enfoque PLACTS com os do educador Paulo Freire, almejando participação social em processos decisórios de temas que envolvam elementos comuns aos pressupostos freireanos, de superação da cultura do silêncio e promoção de percepção de mundo, em que o ser humano deixa de ser objeto histórico e passa a ser sujeito ativo e crítico, 
problematizando os atuais rumos dados ao desenvolvimento científico-tecnológico e constituindo novas sinalizações ao mesmo. De forma que Auler (2007) aponta três dimensões para a referida aproximação no campo educacional: currículo estruturado em torno de temas/problemas reais; dimensão interdisciplinar no enfrentamento desses temas/problemas; busca da democratização de processos decisórios.

Aproximação que perpassa exatamente a busca de temas/problemas condicionados pelo desenvolvimento da CT, em que o educador Paulo Freire sugere a dinamização do processo educacional através da Investigação Temática ${ }^{4}$ na busca de temas geradores que envolvam situações problemáticas, contraditórias, destacando a importância da utilização do diálogo e problematização como forma de obtenção dos temas e devolvendo como uma concepção dialógico-problematizadora da educação, que contraria a educação bancária, a qual apenas realiza e "depósitos que os educandos, meras incidências, recebem pacientemente, memorizam e repetem" (FREIRE, 2020b, p. 80), prática desconexa ao mundo vivido de estudantes. Apesar de Freire não ter preocupação direta com questões curriculares, tais implicações remetem ao campo curricular, em que "configurações curriculares pautadas por abordagem temática sugerem uma maior contextualização" (DELIZOICOV; ANGOTTI; PERNAMBUCO, 2018, p. 189).

Com os pressupostos discutidos anteriormente, essa pesquisa visa a contribuir de forma a refletir sobre aproximações entre Freire-CTS/PLACTS, principalmente ligadas ao Ensino de Ciências.

\section{PERCURSO METODOLÓGICO}

Esta é uma pesquisa qualitativa, de cunho bibliográfico (GIL, 2019), cuja linha metodológica para análise do corpus seguiu a Análise Textual Discursiva (ATD) (MORAES; GALIAZZI, 2016), na qual, a partir de um conjunto de textos, produz-se um novo texto descrevendo e interpretando sentidos e significados destes textos iniciais. Sendo sua análise estruturada em 3 etapas: Unitarização: fragmentação dos textos elaborados por meio das

\footnotetext{
${ }^{4}$ Desenvolvida em cinco etapas, conforme sistematizado por Delizoicov, Angotti e Pernambuco (2018), a partir do terceiro capítulo da obra Pedagogia do Oprimido, de Paulo Freire. Sinteticamente, as etapas correspondem a: Primeira: - levantamento preliminar - que consiste em reconhecer o contexto sócio - histórico - econômicocultural em que vive o estudante; Segunda: - análise das situações e escolha das codificações - Terceira: diálogos decodificadores - obtenção dos Temas Geradores; Quarta: - Redução Temática - trabalho em equipe interdisciplinar; Quinta: - desenvolvimento do programa em sala de aula.
} 
compreensões dos trabalhos. Categorização: as unidades de significado são agrupadas segundo suas semelhanças semânticas e Comunicação: elaboraram-se textos descritivos e interpretativos (metatextos) acerca das categorias temáticas.

Na definição e delimitação do corpus de análise, realizamos o levantamento dos principais trabalhos do repositório do IBICT em sua Biblioteca Digital Brasileira de Teses e Dissertações (BDTD), que tem por objetivo integrar, em um único portal, os sistemas de informação de teses e dissertações existentes no País e disponibilizar para os usuários um catálogo nacional de teses e dissertações em texto integral, possibilitando uma forma única de busca e acesso a esses documentos, até o dia 10/07/2021 estabelecendo os termos de busca: Freire, CTS/PLACTS e Ensino de Ciências, obtendo um total entre teses e dissertações de 38 pesquisas (29 dissertações e 9 teses). Porém, como o critério de seleção se deteve em aproximações entre o educador Paulo Freire, o enfoque CTS e PLACTS na educação, em uma nova seleção restaram 26 pesquisas (19 dissertações 07 teses), as quais identificamos como P1 a P26 (quadro 1). Os resultados do processo de análise são apresentados no próximo item.

\begin{tabular}{|c|c|c|c|c|}
\hline $\mathrm{N}^{\mathrm{o}}$ & Título & Autor & Ano & Instituição \\
\hline P1 & $\begin{array}{l}\text { Abordagem de temas polêmicas no currículo da } \\
\text { EJA: o caso do "florestamento" no RS } \\
\text { (Dissertação). }\end{array}$ & $\begin{array}{l}\text { FORGIARINI, } \\
\text { M. S. }\end{array}$ & 2007 & UFSM \\
\hline $\mathrm{P} 2$ & $\begin{array}{l}\text { Abordagem CTS e ensino médio: espaços de } \\
\text { articulação (Dissertação). }\end{array}$ & $\begin{array}{l}\text { STRIDER, R. } \\
\text { B. }\end{array}$ & 2008 & USP \\
\hline P3 & $\begin{array}{l}\text { Professor "fazedor" de currículos: desafios no } \\
\text { estágio curricular supervisionado em ensino de } \\
\text { ciências. (Dissertação). }\end{array}$ & HUNSCHE, S. & 2010 & UFSM \\
\hline $\mathrm{P} 4$ & $\begin{array}{l}\text { Ensino de psicologia organizacional em cursos da } \\
\text { área tecnológica: o que é e o que pode ser } \\
\text { (Dissertação). }\end{array}$ & $\begin{array}{l}\text { GONÇALVES, } \\
\text { C. A. }\end{array}$ & 2012 & UTFPR \\
\hline P5 & $\begin{array}{l}\text { Relações entre saneamento-química-meio ambiente } \\
\text { na educação profissional e tecnológica numa } \\
\text { perspectiva crítico transformadora (Tese). }\end{array}$ & LEAL, A. L. & 2012 & UFSC \\
\hline P6 & $\begin{array}{l}\text { O referencial teórico de Paulo Freire no ensino de } \\
\text { ciências e na educação CTS: um estudo } \\
\text { bibliométrico e epistemológico (Tese). }\end{array}$ & $\begin{array}{l}\text { LOPES, G. Z. } \\
\text { L. }\end{array}$ & 2013 & UFSCar \\
\hline P7 & $\begin{array}{l}\text { Os três momentos pedagógicos no ensino de } \\
\text { ciências na educação de jovens e adultos da rede } \\
\text { pública de Goiânia, Goiás: o caso da dengue } \\
\text { (Dissertação). }\end{array}$ & $\begin{array}{l}\text { LYRA， D. G. } \\
\text { G. }\end{array}$ & 2013 & UFG \\
\hline P8 & $\begin{array}{l}\text { Perspectiva CTS em estágios curriculares em } \\
\text { espaços de divulgação científica: contributos para a } \\
\text { formação inicial de professores de ciências e } \\
\text { biologia (Tese). }\end{array}$ & $\begin{array}{l}\text { PRUDÊNCIO, } \\
\text { C. A. V. }\end{array}$ & 2013 & UFSCar \\
\hline P9 & $\begin{array}{l}\text { Intervenções curriculares na perspectiva da } \\
\text { abordagem temática: avanços alcançados por } \\
\text { professores de uma escola pública estadual do RS } \\
\text { (Dissertação). }\end{array}$ & $\begin{array}{l}\text { GIACOMINI, } \\
\text { A. }\end{array}$ & 2014 & UFSM \\
\hline P1 & Uma experiência na formação de professores em & LUNARDI, G. & 2014 & UFSC \\
\hline
\end{tabular}




\begin{tabular}{|c|c|c|c|c|}
\hline 0 & $\begin{array}{l}\text { Timor-Leste: das condições de produção aos } \\
\text { sentidos construídos no enfoque CTS (Dissertação) }\end{array}$ & & & \\
\hline $\begin{array}{l}\mathrm{P} 1 \\
1\end{array}$ & $\begin{array}{l}\text { Educação científica e tecnológica para a } \\
\text { participação: Paulo Freire e a criatividade (Tese). }\end{array}$ & $\begin{array}{l}\text { BARBOSA, R. } \\
\text { G. }\end{array}$ & 2014 & UEL \\
\hline $\begin{array}{l}\mathrm{P} 1 \\
2\end{array}$ & $\begin{array}{l}\text { Compreensões de professores sobre abordagens da } \\
\text { biotecnologia no ensino de química (Dissertação). }\end{array}$ & $\begin{array}{l}\text { MARCELINO, } \\
\text { L. V. }\end{array}$ & 2014 & UFSC \\
\hline $\begin{array}{l}\mathrm{P} 1 \\
3\end{array}$ & $\begin{array}{l}\text { Abordagem temática e a introdução de conteúdos de } \\
\text { física moderna e contemporânea no ensino médio: } \\
\text { uma primeira aproximação (Dissertação). }\end{array}$ & FIGUEIRA, R. & 2014 & UFSCar \\
\hline $\begin{array}{l}\mathrm{P} 1 \\
4\end{array}$ & $\begin{array}{l}\text { Projetos temáticos e enfoque CTS na educação } \\
\text { básica: caracterização dos trabalhos apresentados } \\
\text { por autores brasileiros, espanhóis e portugueses nos } \\
\text { seminários ibero-americanos de CTS (Dissertação). }\end{array}$ & $\begin{array}{l}\text { GONÇALVES, } \\
\text { R.S. }\end{array}$ & 2014 & UNIFEI \\
\hline $\begin{array}{l}\text { P1 } \\
5\end{array}$ & $\begin{array}{l}\text { "Arroio Cadena: cartão postal de Santa Maria"? } \\
\text { possibilidades e desafios em uma reorientação } \\
\text { curricular na perspectiva da abordagem temática } \\
\text { (Dissertação). }\end{array}$ & CENTA, F. G. & 2015 & UFSM \\
\hline $\begin{array}{l}\text { P1 } \\
6\end{array}$ & $\begin{array}{l}\text { Educação científica e tecnológica em cursos de } \\
\text { engenharia com apoio dos espaços sociais da web } \\
2.0 \text { (Tese). }\end{array}$ & $\begin{array}{l}\text { SCHWERTL, } \\
\text { S. L. }\end{array}$ & 2016 & UFSC \\
\hline $\begin{array}{l}\text { P1 } \\
7\end{array}$ & $\begin{array}{l}\text { Abordagem de interações entre Ciência, Tecnologia } \\
\text { e Sociedade no ensino de química na articulação } \\
\text { com a literatura (Dissertação). }\end{array}$ & $\begin{array}{l}\text { OLIVEIRA, D. } \\
\text { Q. }\end{array}$ & 2017 & UFSC \\
\hline $\begin{array}{l}\text { P1 } \\
8\end{array}$ & $\begin{array}{l}\text { Contextualização do ensino de química por meio do } \\
\text { enfoque CTS atrelado à pedagogia de Paulo Freire } \\
\text { (Dissertação). }\end{array}$ & JESUS, M. P. & 2017 & UFS \\
\hline $\begin{array}{l}\text { P1 } \\
9\end{array}$ & $\begin{array}{l}\text { A pesquisa na formação inicial de professores de } \\
\text { ciências no Timor-Leste: contribuições do grupo de } \\
\text { estudos sobre ensino de ciências e tecnologia } \\
\text { (GEECITE) (Tese). }\end{array}$ & $\begin{array}{l}\text { CUNHA, F. S. } \\
\text { R. }\end{array}$ & 2017 & UFSC \\
\hline $\begin{array}{l}\mathrm{P} 2 \\
0\end{array}$ & $\begin{array}{l}\text { Ensino de física a partir da articulação Freire-CTS: } \\
\text { lançando um novo olhar sobre as escolas do campo } \\
\text { (Dissertação). }\end{array}$ & DIAS, F. F. & 2018 & UFSM \\
\hline $\begin{array}{l}\mathrm{P} 2 \\
1\end{array}$ & $\begin{array}{l}\text { Usuários e produção da existência: contribuições de } \\
\text { Alvaro Vieira Pinto e Paulo Freire à interação } \\
\text { humano-computador (Tese). }\end{array}$ & $\begin{array}{l}\text { GONZATTO, } \\
\text { R. F. }\end{array}$ & 2018 & UTFPR \\
\hline $\begin{array}{l}\mathrm{P} 2 \\
2\end{array}$ & $\begin{array}{l}\text { Abordagem de temas no ensino de ciências: } \\
\text { reflexões para processos formativos de professores } \\
\text { (Dissertação). }\end{array}$ & $\begin{array}{l}\text { FONSECA, E. } \\
\text { M. }\end{array}$ & 2019 & $\begin{array}{l}\text { UNIPAMP } \\
\text { A }\end{array}$ \\
\hline $\begin{array}{l}\mathrm{P} 2 \\
3\end{array}$ & $\begin{array}{l}\text { Contribuição da horta escolar para uma educação } \\
\text { problematizadora nos anos finais do ensino } \\
\text { fundamental (Dissertação). }\end{array}$ & DINIZ, F. & 2019 & Unesp \\
\hline $\begin{array}{l}\mathrm{P} 2 \\
4\end{array}$ & $\begin{array}{l}\text { Educação CTS/CTSA baseada em Paulo Freire: } \\
\text { produção de saberes de ciências biológicas e } \\
\text { geociências no ensino médio no noroeste capixaba } \\
\text { (Dissertação). }\end{array}$ & JESUS, C. P. F. & 2019 & UFES \\
\hline $\begin{array}{l}\mathrm{P} 2 \\
5\end{array}$ & $\begin{array}{l}\text { Reorientação curricular na disciplina química via } \\
\text { tema gerador: uma aproximação Freire-CTS } \\
\text { (Dissertação) }\end{array}$ & JOTA, A. B. F. & 2019 & UFRN \\
\hline $\begin{array}{l}\mathrm{P} 2 \\
6\end{array}$ & $\begin{array}{l}\text { Articulação Freire-CTS na formação de educadoras } \\
\text { dos anos iniciais (Dissertação). }\end{array}$ & $\begin{array}{l}\text { MARQUES, S. } \\
\text { G. }\end{array}$ & 2019 & UFSM \\
\hline
\end{tabular}

Quadro 1 - Pesquisas que compõem o corpus de análise

Fonte: SCHWAN; SANTOS, 2021. 


\section{RESULTADOS, OS ENUNCIADOS EMERGENTES}

Durante a realização da etapa de unitarização, identificamos 106 unidades de significado ou unidades de análise, obtidas a partir do processo de fragmentação ou desconstrução dos textos, que contribuíram para percebermos os sentidos dos textos em diferentes limites e seus pormenores, sendo o próprio pesquisador que decide em que medida fragmentará seus textos. "Cada unidade constitui um elemento de significado pertinente ao fenômeno de análise [...]" (MORAES; GALIAZZI, 2016, p. 41), neste caso, as unidades sempre estão em consonância aos objetivos da pesquisa.

Após essa identificação, emergiram no processo de categorização quatro categorias: i) Diálogos na estruturação curricular sob aproximação Freire-CTS, contendo 46 unidades de significado; ii) Busca de participação e democratização em processos decisórios diante de temas científico tecnológicos, 42 unidades de significado; iii) Encontro com a educação problematizadora de freire e a suposta neutralidade da Ciência-Tecnologia, 30 unidades de significado e iiii) Divergências e desafios entre abordagens Freire-CTS/PLACTS, 15 unidades de significado.

Para a discussão das categorias utilizamos diversas unidades de contexto (recortes/fragmentos do corpus), “[...] fragmentos relativamente amplos de textos que delimitam o contexto das unidades de análise" (MORAES; GALIAZZI, 2016, p. 78), com o propósito de dar maior contextualização para as "unidades de significados" encontradas na etapa de unitarização, ou seja, dentro das unidades de contexto são encontradas unidades de significado e uma mesma unidade de significado pode se repetir em mais de uma categoria.

\subsection{Diálogos na estruturação curricular sob aproximação Freire - CTS}

Esta primeira categoria consiste em configurações curriculares "em torno de temas, de problemas reais e contemporâneos" (SANTOS, 2016, p. 66). Na busca de maior participação e democratização em decisões de temas/problemas sociais que envolvam Ciência-Tecnologia (AULER; DELIZOICOV, 2006), partindo de uma leitura crítica da realidade na busca do que Freire (2020b) denomina de temas geradores, sugerindo a dinamização do processo educacional através da Investigação Temática, discutida anteriormente. Portanto, uma "perspectiva curricular cuja lógica de organização é estruturada com base em temas, com os 
quais são selecionados os conteúdos de ensino das disciplinas. Nessa abordagem, a conceituação científica da programação é subordinada ao tema" (DELIZOICOV; ANGOTTI; PERNAMBUCO, 2018, p. 189). Temas que, no processo de investigação temática, necessitam de problematização, rompendo com situações-limites que se apresentam aos homens como "determinantes históricas, esmagadoras, em face das quais não lhes cabe outra alternativa, senão adaptar-se" (FREIRE, 2020b, p. 130), que, no ato de problematizar os temas, seja possível visualizar soluções aos problemas, alcançando o inédito viável, de forma que se impõe a ação libertadora aos homens (FREIRE, 2020b).

A aproximação entre Freire-CTS na análise das pesquisas, em um de seus pontos, se estabelece na estruturação curricular envolta de temas/problemas, que "pensada a partir de temas em consonância com as demandas sociais possibilita discutir novos caminhos para uma Política-Científica-Tecnológica (PCT), de modo que as problemáticas de determinada localidade direcionem esses rumos" (P22, p. 30). Tal estruturação curricular, pensada a partir de temas e que se mostra como opção, advém da crítica que é feita ao currículo tradicional como definições a priori, em que "[...] os conteúdos e as atividades abordadas nas escolas brasileiras são indicados pelos Parâmetros Curriculares Nacionais. Tratam-se de temas préestabelecidos a serem cumpridos num determinado período do calendário escolar" (P6, p. 105), consequentemente, conteúdos, sem conexão com a realidade de estudantes. "Então, um ensino que objetive a formação de educandos capazes de atuar de forma consciente e transformadora na sociedade em que vivem rompe com a linearidade do ensino e preocupa-se com uma contextualização do conteúdo à realidade do educando" (P7, p. 49), unidades de contexto que apontam uma inversão curricular, superando o modelo tradicional conteudista e alcançando um modelo crítico ligado ao mundo de vida de docentes e discentes.

Nesse cenário, ficou claro, nas pesquisas analisadas, que, além de tratar da formação de estudantes, é imprescindível considerar a formação de professores e seu planejamento curricular, ressaltando "a necessidade de aprofundar discussões sobre a perspectiva temática em processos formativos de professores, bem como a organização de currículos sensíveis a questões relevantes do contexto" (P22, p. 31). E, sob a perspectiva de configuração de um currículo alicerçado em Freire-CTS, os temas serão "incluídos e discutidos previamente no currículo, juntamente com os professores, e inseridos no planejamento das escolas, parte do projeto político pedagógico" (P6, p. 105). De igual maneira, a formação inicial e continuada docente é apontada, nas pesquisas, como necessária para o desenvolvimento do trabalho 
interdisciplinar, como destacado pela pesquisa P 20: "Para que haja um trabalho interdisciplinar há a necessidade que a formação de professores, tanto inicial como continuada, de conta da integração dos diversos conhecimentos de forma que os professores possam realizar um trabalho interdisciplinar nas escolas" (p. 68). Relato que enfatiza a necessidade de investimento na formação docente (FERST; GHEDIN, 2016).

E, sob a ângulo de ampliar a discussão, tanto da formação docente como acerca do planejamento escolar, ambos denotam aspectos de participação em equipe interdisciplinar, característica importante da Investigação Temática discutida anteriormente. Freire (2020b) destaca o trabalho sob diferentes ângulos, inicialmente desenvolvido em equipe interdiciplinar, que adiante, pela complexidade dos temas, requer análises profundas e disciplinares, sendo este processo denominado de redução temática, presente na quarta etapa da Investigação Temática, na qual cada "especialista busca os seus núcleos fundamentais as quais constituem as unidades de aprendizagem” (FREIRE, 2020, p. 160), assim definindo os conhecimentos necessários para a compreensão do tema gerador. A abordagem com enfoque CTS salienta, de igual forma, a abordagem interdisciplinar para discussão de temas com relevância social, porém divergem quanto à origem do tema, discussão mais detalhada na última categoria deste trabalho.

Nesta categoria, a análise baseou-se na estruturação curricular sob a aproximação de Freire-CTS, utilizando-se da investigação temática para busca de temas com maior significado aos estudantes, contudo temas advindos de problemáticas sociais, como forma de superação de situações-limites, a fim de tornarem-se sujeitos críticos, dar voz a sujeitos anteriormente silenciados pelos rumos da CT, tema em debate na seguinte categoria.

\subsection{Busca de participação e democratização em processos decisórios diante de temas científico tecnológicos}

A articulação entre Freire e CTS na busca de uma maior participação e, consequentemente, na democratização nos processos de decisão em temáticas sociais envolvendo a CT, possui elementos comuns aos de Freire, que na superação da cultura do silêncio promovam uma maior percepção de mundo, em que o ser humano deixa de ser objeto histórico e passa a ser sujeito ativo e crítico, problematizando os atuais rumos dados ao desenvolvimento científico-tecnológico e novas sinalizações ao mesmo. "Para tal, precisa-se 
de uma compreensão crítica das interações CTS, de uma leitura de mundo, do mundo contemporâneo, cada vez mais condicionado pelo desenvolvimento científico-tecnológico" (SANTOS, 2016, pp. 66-67). E, por defender uma cultura de participação, mediante a apenas essa, é possível democratizar os processos decisórios a partir de uma leitura crítica da realidade (FREIRE, 2020a), “[...] de modo a superar esta cultura do silêncio e possibilitar que os educandos participem da construção de sua própria história, rompendo com seu silêncio e submissão" (P1, p. 36).

Dentro de um processo de problematização da realidade, que visa à compreensão crítica do desenvolvimento da CT, antecedente a essa questão, é necessário refletir sobre as construções históricas (AULER; DELIZOICOV, 2015) presentes nas discussões CTS, em que parte da sociedade será levada a sustentar uma postura de fatalismo que, para Freire (2020a), trata-se de "[...] convencer-nos de que nada podemos contra a realidade social que, de histórica e cultural, passa a ser ou virar 'quase natural"” (FREIRE, 2020a, p. 21). Ideologia que cria mitos ${ }^{5}$ ou verdades absolutas, frutos da construção histórica da atividade científicotecnológica, lógica que enaltece processos hegemônicos opressores, diante da sociedade oprimida e silenciada, limitando sua ação, ocasionada por uma leitura de mundo, creditada em estar livre de valores ou intencionalidades, ou seja, neutra, fortalecendo mitos criados pela falta de problematizações, essenciais e intrínsecas para a leitura crítica do mundo.

[...] a sociedade contemporânea é envolta por mitos relacionados à ciência e à tecnologia que acabam por estarem presentes nas leituras de mundo dos indivíduos. A consequência disso é que como a leitura do mundo precede a leitura da palavra, muitas vezes o ato de ler, pode endossar esses mitos. Por esse motivo é que a leitura deve ser realizada de modo que esses mitos sejam desvelados e a consciência crítica comece aflorar (P17, p. 53).

No entanto, desconsiderar a leitura de mundo, seu saber de experiência feito, é ignorar aos grupos populares sua explicação de mundo, da qual faz parte sua compreensão. Faz-se necessário o diálogo, para que este seja desafiado à reflexão e à necessidade de superar certos saberes (FREIRE, 2020a, p. 101). A aproximação entre Freire-CTS, nas pesquisas analisadas,

\footnotetext{
${ }^{5}$ Os mitos referidos nesta categoria são sustentados por três construções históricas, que segundo Auler (2002) são: a) Superioridade do modelo de decisões tecnocráticas - consiste na ideia de que as decisões devem ser tomadas apenas por uma pequena parcela da sociedade, os especialistas e de forma neutra, excluindo a maior parte da sociedade das decisões; b) Perspectiva salvacionista da CT - creditadas a ela, em algum momento do presente ou do futuro, a possibilidade de resolução dos problemas sociais hoje existentes, conduzindo, desta forma, a humanidade ao bem estar social; c) Determinismo tecnológico - a tecnologia é que define os limites do que uma sociedade pode ou não fazer. A inovação tecnológica é autônoma e livre de influências, ou seja, neutra.
} 
propõe a superação da cultura do silêncio, na concepção dialógica de Freire, que, realizada com o estudante, "não é apenas uma troca de informações, ou uma conversa, mas sim um esforço em busca da compreensão e transformação da realidade" (P2, p. 65).

O desvelamento de mitos, discutidos nesta categoria, precede do diálogo, bem como da superação da suposta neutralidade associada à CT, neutralidade que serve como base de sustentação destes mitos. Por meio de uma educação problematizadora, torna-se possível sua superação, fonte de discussão da seguinte categoria.

\subsection{Encontro com a educação problematizadora de Freire e a suposta neutralidade da ciência-tecnologia.}

A complexidade de problemas contemporâneos marcados pela componente científicotecnológica sugere sujeitos críticos na tomada de decisões. Igualmente, a aproximação FreireCTS procura, também, problematizar aspectos quanto à suposta neutralidade da CT, na qual ela está entendida como o isolamento dos conceitos em relação ao ambiente em que são gerados, ou seja, a produção científico-tecnológica é independente do contexto social, evitando que técnicos ou especialistas, os autores que promovem o desenvolvimento de mais $\mathrm{CT}$, percebam o interesse de determinados grupos, que podem dar rumos diferentes à inovação (SANTOS, 2012), legitimando processos decisórios tecnocráticos, alicerçadas na “[...] possibilidade de neutralizar/eliminar o sujeito do processo científico-tecnológico. O expert (especialista/técnico) pode solucionar os problemas, inclusive os sociais, de um modo eficiente e ideologicamente neutro" (AULER, 2003, p. 75), criando a ideia de técnicos e especialistas assépticos diante de influências externas em sua tomada de decisão, percepção semelhante a P17, que, ao contrariar a ideia de CT neutra, defende a humanização da atividade científico-tecnológica.

\footnotetext{
A ideia de que a ciência e a tecnologia são autônomas, neutras, livres de valores, destitui aspectos humanos dessas atividades, ficando legadas apenas aos aspectos técnicos. Se a educação CTS defende que se deve humanizar a atividade científica e tecnológica, a leitura em uma perspectiva freireana possui uma grande dimensão social que favorece o humanismo crítico. O sujeito transforma o mundo e sofre os efeitos de sua própria transformação (P17, 2017, p. 60).
}

Para tanto, o modelo de decisões tecnocráticas, tido como livre de valores, é alimentado pela neutralidade, que se mostra ineficaz, apenas quando existir a real participação 
democrática nas decisões envolvendo $\mathrm{CT}$, um processo com base crítica, fundada na problematização apontando para “[...] a necessidade de um redirecionamento da PCT que seja coerente com as demandas da sociedade, para que os conhecimentos envolvidos estejam em consonância com as necessidades locais/regionais, gerando uma agenda de pesquisa socialmente relevante" (P22, p.30).

Dagnino (2014) alerta sobre os valores que contemporaneamente fundamentam a agenda de pesquisa intrinsecamente voltados ao mercado de trabalho. O mesmo propõe a reorganização das atividades científico-tecnológicas, as quais sejam voltadas para as demandas, aos problemas reais da sociedade, corroborado pela pesquisa P22 discutida anteriormente. Neste âmbito, promover a problematização de questões científico-tecnológicas presentes em diferentes contextos, nos quais são negligenciados por uma falsa ideia atribuída aos três mitos supracitados, se faz necessária, como parte de um desvelamento de um mundo aos sujeitos que dele fazem parte, perspectiva corroborada por todas as pesquisas analisadas, as quais, em menor ou maior aprofundamento, utilizam o mesmo referencial deste trabalho.

Por consequência, a problematização surge como forma de superação da concepção/consciência ingênua sobre CTS, esta que é fruto de construções históricas (AULER, 2018), debatidas na categoria anterior, sustentadas pelo modelo de decisões tecnocráticas determinando a CT como livre de valores ou neutra, suscitando posturas fatalistas por parte da sociedade, o que torna isto um processo de retroalimentação, ou seja, as construções históricas estimulam fatalismos, estes que, por sua perpetuação, continuam sustentando construções históricas no campo da CT. Campo não aprofundado por Freire, mas os trabalhos analisados até aqui utilizam suas categorias para seu desenvolvimento, enfatizando a aproximação Freire-CTS. Porém, os mesmos trabalhos apontam divergências e desafios a serem enfrentados entre as abordagens, que buscam, junto ao conceito de participação, enraizamentos latino-americanos encontrados nos pressupostos do PLACTS apresentados adiante na última categoria deste trabalho.

\subsection{Divergências e desafios entre abordagens Freire-CTS/PLACTS}

Nesta última categoria são apontadas algumas divergências entre as referidas abordagens. Freire a partir da educação libertadora, aponta uma maneira em que o "[...] educando pudesse tomar consciência da sua situação existencial e pudesse agir sobre ela para 
transformá-la em direção à construção de uma sociedade mais justa e igualitária” (SANTOS, 2008, p. 117). Já quanto ao movimento CTS, que surgiu em países de Primeiro Mundo, sua perspectiva seguiu o contexto destes países. “As questões centrais discutidas nas propostas curriculares com enfoque CTS nesse movimento centravam-se muito mais nos impactos tecnológicos na sociedade e, sobretudo, em suas consequências ambientais [...]” (SANTOS, 2008, p. 118).

Divergência, também, denotada em relação ao estudo de temas, mais especificamente quanto ao seu surgimento. Como surgem os temas que são objetos de estudo? "Na perspectiva de Freire, os temas de aprendizagem surgem com uma efetiva participação da comunidade escolar, enquanto que nos encaminhamentos dados pelo enfoque CTS, essa dinâmica está ausente, sendo definida pelo professor" (P1, p. 110). Aspecto já denotado pela pesquisa realizada por Auler, Dalmolin e Fenalti (2009), que discute a natureza dos temas em Freire e no enfoque CTS, que utilizou como fontes para sua pesquisa: periódicos, anais de eventos, coletânea de cadernos e guias didáticos, alcançando resultado semelhantes aos indicados neste trabalho. Freire (1987) utiliza a investigação temática como forma de obtenção de situações problemáticas, contraditórias dos estudantes e da comunidade escolar, destacando a importância da utilização do diálogo e da problematização. Já CTS não demostra uma efetiva participação de nenhum dos sujeitos referidos.

Discussão ampliada pela P22 sobre a sistematização da investigação temática freireana na busca pelo tema gerador e a seleção de conteúdos no currículo CTS. Logo, a pesquisa defende que:

[...] todo Tema Gerador é Tema CTS, pois está vinculado a questões da Sociedade, CT, porém não é todo Tema CTS que possui o potencial para tornar-se um Tema Gerador já que é necessária a realização do processo de Investigação Temática para identificar as situações-limite (P22, p. 29).

Dando continuidade às divergências em relação ao estudo de temas nas perspectivas das abordagens Freire-CTS quanto à abrangência dos temas, P2 destaca que "[...] as ideias freireanas caminham no sentido de manter o foco na realidade local, a perspectiva curricular CTS tende a escolher temas de alcance mais global e geral, sem se ater muito a contextos específicos" (p. 35). Cabe salientar que, mesmo tendo um alcance global/geral, continuam sendo identificados como temas. Divergência, tal como notada por Auler, Dalmolin e Fenalti (2009), em que Freire aponta com temas locais, já CTS com uma abrangência mais geral.

No que diz respeito à relação de tema/conteúdo, ou seja, conteúdo subordinado ao 
tema ou tema subordinado ao conteúdo, as pesquisas analisadas que se referenciam em Freire, na tendência de suas configurações curriculares os conhecimentos/conteúdos estão em função do tema, principalmente por utilizar a perspectiva dos temas geradores, em CTS a relação tema/conteúdo apresenta variações, “[...] em que o tema é trabalhado em função de conteúdos definidos a priori” (AULER; DALMOLIN; FENALTI, 2009, p. 78).

Em parte, os objetivos dessa junção de referências na área de ensino em ciências se explicam pelos ideais freireanos contribuírem com dimensões que podem ser concebidas como complementáveis e articuláveis ao campo CTS (AULER, 2018), dimensões já destacadas no referencial deste trabalho, sendo o currículo estruturado em torno de temas/problemas reais; dimensão interdisciplinar no enfrentamento desses temas/problemas; busca da democratização de processos decisórios (AULER, 2007). Aproximação que leva, posteriormente, à transposição para os pressupostos do PLACTS no campo educacional (AULER, 2018), corroborado por P15, que enfatiza a necessidade de voltar os olhares ao campo educacional, que, "[...] enquanto uma das dimensões essenciais para a construção de uma sociedade mais justa e igualitária, pode contemplar em seus currículos a abordagem Freire/CTS/PLACTS” (p. 46). A mesma pesquisa vai além, e destaca uma possível maneira de dar aporte a esta abordagem: "Uma possível maneira de instrumentalizar esse viés Freire/PLACTS seria investir nas pesquisas nas universidades, nas políticas públicas, na formação inicial docente, e para aqueles que já estão nas escolas, uma saída seria a formação continuada [...]" (P15, p. 46-47).

Destaca-se a importância da formação de professores, pois de nada adianta um currículo de aproximações entre tais referenciais quando não há formação docente adequada ao viés proposto com bem descreve P3, sobre o novo tipo de profissionais a partir de propostas Freire/CTS, pois já “[...] que na concepção dialógica da educação ele deixa de depositar os conteúdos na cabeça dos educandos, para assumir o papel de catalisador do processo de ensino e aprendizagem" (p. 47), em contradição à lógica tradicional e disciplinar de ensino.

Portanto, a articulação desta perspectiva (CTS/PLACTS-Freire), analisada neste trabalho, é " $[\ldots]$ pensada a partir de temas em consonância com as demandas sociais possibilita discutir novos caminhos para uma PCT (Política-Científica-Tecnológica), de modo que as problemáticas de determinada localidade direcionem esses rumos" (P22, p. 30), um redimensionamento da PCT que seja condizente com as demandas da sociedade, fortalecendo 
o processo de participação nas decisões contribuindo para práticas mais democráticas, ao tempo que aprofunda o conceito de participação "[...] visto que nos pressupostos freireanos essa participação compreende a superação da 'cultura do silêncio' e na Educação CTS/PLACTS a superação dos modelos de decisões tecnocráticas” (P22), potencializando a cultura de participação nas duas perspectivas.

\section{5 À GUISA DE UM ARREMATE}

Aproximações entre o educador Paulo Freire aos referenciais ligados ao enfoque CTS, começam a tomar maiores contornos, principalmente no Ensino de Ciências, como destacado nas pesquisas. Apontam configurações curriculares, a partir dessa aproximação e tendo como ponto de partida a busca por temas, fazendo uso da Investigação Temática para alcançar temas de contradições advindas de problemáticas proporcionadas pelo uso da CT, partindo da realidade de estudantes, a fim de obter consciência crítica na tomada de decisões que envolvam tais temáticas. Porém, dentro do processo de Investigação Temática, existe a necessidade de reflexão quanto às construções históricas proporcionadas pela CT, que em práticas tradicionais são inexistentes, provocando o silêncio aos oprimidos, que têm suas necessidades ignoradas, sua participação limitada, estes que, levados a acreditar na fatalidade para a sua atual existência, contradição que começa a romper-se pelo diálogo problematizador realizado em conjunto ao estudante em busca da compreensão da realidade, características Freireanas, dialogicidade e problematização. O PLACTS, apesar de ser um movimento que faz a crítica à PCT adotada na América Latina, inspirada em países capitalistas do norte e sua transmissão linear da CT, busca no campo educacional aproximação ao referencial de Paulo Freire, que, sob este enfoque, objetiva pensar sobre temas locais, que apontem temas/problemas, para adiante de novos rumos em uma percepção crítica, democrática e uma maior percepção de mundo, questões pertinentes ao desenvolvimento científico-tecnológico contemporâneo marcado por demandas sociais.

Portanto, entendemos que as aproximações da abordagem CTS e a concepção freireana de educação nas pesquisas revisadas denotam transformações no ensino, principalmente, ao ensino de Ciências, foco desta análise. Essa aproximação sinaliza uma nova configuração curricular, baseada na problematização de temas/problemas de relevância social e que auxiliem os sujeitos em formação, a emergirem de uma consciência ingênua para 
uma concepção crítica da realidade e o substancial crescimento de pesquisa que apontam o PLACTS como referencial em âmbito educacional.

\section{REFERÊNCIAS}

AULER, D. Articulação Entre Pressupostos do Educador Paulo Freire e do Movimento CTS: Novos Caminhos Para a Educação em Ciências. CONTEXTO \& EDUCAÇÃO, v. 22 n. 77, p. 167-188, 2007. https://doi.org/10.21527/2179-1309.2007.77.167-188

AULER, D. Cuidado! Um cavalo viciado tende a voltar para o mesmo lugar. $1^{\mathrm{a}}$ ed. Curitiba. Appris, 2018.

AULER, D. Enfoque Ciência-Tecnologia-Sociedade: Pressupostos para o contexto brasileiro. Ciência e Ensino, v.1, n. especial, p. 1-20, 2007. Disponível em: https://edisciplinas.usp.br/pluginfile.php/4960414/mod_folder/content/0/ENFOQUE\%20CI\% C3\%8ANCIA-TECNOLOGIASOCIEDADE.pdf?forcedownload=1. Acesso em 22 de jul. 2021.

AULER, D.; DALMOLIN, A. M. T.; FENALTI, V. S. Abordagem Temática: natureza dos temas em Freire e no enfoque CTS. Alexandria, v. 2, n. 1, p. 67-84, 2009. Disponível em: https://periodicos.ufsc.br/index.php/alexandria/article/view/37915. Acesso em 22 de jul. 2021.

AULER, D.; DELIZOICOV, D. Ciência-Tecnologia-Sociedade: relações estabelecidas por professores de ciências. Revista Electrónica de Enseñanza de Las Ciencias, v. 5, n. 2,p. 337-355, 2006. Disponível em:

http://reec.uvigo.es/volumenes/volumen5/ART8_Vol5_N2.pdf. Acesso em: 22 de jul. 2021.

AULER, D.; DELIZOICOV, D. Investigação de temas CTS no contexto do pensamento latino-americano. Linhas Críticas, v. 21, n. 45, p. 275-296, 2015.

https://doi.org/10.26512/lc.v21i45.4525.

DAGNINO, R. Mais além da participação pública na ciência: buscando uma reorientação dos estudos sobre ciência, tecnologia e sociedade em ibero-américa. CTS+I - Revista

iberoamericana de Ciencia, Tecnologia, Sociedad e Innovación. n. 7, p. 01-15, 2006.

Disponível em: https://dialnet.unirioja.es/servlet/articulo? codigo=3112229. Acesso em: 22 jul. 2021.

DAGNINO, R. Neutralidade da ciência e determinismo tecnológico: um debate sobre a tecnociência. Campinas, SP, Unicamp, 2008.

DAGNINO, R. A tecnologia social e seus desafios. In: Tecnologia Social: contribuições conceituais e metodológicas. Campina Grande, EDUEPB, 2014.

DAGNINO, R. O que é o PLACTS (pensamento latino-americano em ciência, tecnologia e sociedade)? In: Neder, R. T. (Org.). CTS - ciência tecnologia sociedade e a produção de 
conhecimento na Universidade. Brasília: Observatório do Movimento pela Tecnologia Social na América Latina, 2013.

DELIZOICOV, D.; ANGOTTI, J. A.; PERNAMBUCO, M. M. Ensino de ciências: fundamentos e métodos. 5a . ed. São Paulo: Cortez, 2018.

FERST, E. M.; GHEDIN, E. L. Panorama das publicações nos ENPECS sobre CTS nos anos iniciais do ensino fundamental. REAMEC - Rede Amazônica de Educação em Ciências e Matemática, $[S . \quad$ l.], $\quad$ v. $4, \quad$ n. $1, \quad$ p. 57-75, 2016. Disponível em: https://periodicoscientificos.ufmt.br/ojs/index.php/reamec/article/view/5317. Acesso em: 17 out. 2021.

FREIRE, P. Pedagogia da Autonomia: saberes necessários à prática educativa. $63^{\mathrm{a}}$. ed São Paulo, Paz e Terra, 2020a.

FREIRE, P. Pedagogia do Oprimido. 71 a . ed. Rio de Janeiro, Paz e Terra, 2020b.

GIL, A. C. Como elaborar projetos de pesquisa. $7^{\circ}$. ed. São Paulo, Atlas, 2019.

MORAES, R.; GALIAZZI, M. C. Análise Textual Discursiva. 3.ed. Ijuí, Editora Unijuí, 2016.

ROSO, C. C.; AULER, D. A participação na construção do currículo: práticas educativas vinculadas ao movimento CTS. Ciência \& Educação, v. 22, n. 2, p. 371-389, 2016. https://doi.org/10.1590/1516-731320160020007.

SANTOS, W. L. P. Educação científica humanística em uma perspectiva freireana: resgatando a função do ensino de CTS. Alexandria - Revista de Educação em Ciência e Tecnologia, v. 1, n. 1, p. 109-131, 2008. Disponível em https://periodicos.ufsc.br/index.php/alexandria/article/view/37426/28747. Acesso em: $22 \mathrm{de}$ jul. 2021.

SANTOS, R. A. Busca de uma participação social para além da avaliação de impactos da ciência-tecnologia na sociedade: sinalizações de práticas educativas cts. 2016. 205 f. Tese (Doutorado) - Curso de Programa de Pós-graduação em Educação, Universidade Federal de Santa Maria, Santa Maria, Rs, 2016. Disponível em:

https://repositorio.ufsm.br/bitstream/handle/1/3513/SANTOS,\%20ROSEMAR\%20AYRES\% 20DOS.pdf? sequence=1\&isAllowed=y. Acesso em: 22 de jul. 2021.

SANTOS, R. A.; ROSA, S. E. AULER, D. A não neutralidade da ciência-tecnologia em abordagens CTS no contexto brasileiro. Atas... IX Encontro Nacional de Pesquisa em Educação em Ciências, 2013. Disponível em:

http://www.nutes.ufrj.br/abrapec/ixenpec/atas/resumos/R1279-1.pdf. Acesso em: 22 de jul. 2021.

STRECK, D.; REDIN, E.; ZITKOSKI, J. J. (Org.). Dicionário Paulo Freire. Belo Horizonte, Editora Auténtica, 2015. 
STRIEDER, R. B. Abordagens CTS na educação científica no Brasil: Sentidos e perspectivas. 2012. 283 f. Tese (Doutorado em Ciências) - Universidade de São Paulo, São Paulo, 2012. Disponível em: https://www.teses.usp.br/teses/disponiveis/81/81131/tde13062012-112417/publico/Roseline_Beatriz_Strieder.pdf. Acesso em: 22 de jul. 2021.

\section{APÊNDICE 1}

\section{AGRADECIMENTOS}

Não se aplica.

\section{FINANCIAMENTO}

Não se aplica.

\section{CONTRIBUIÇÕES DE AUTORIA}

Resumo/Abstract/Resumen: Me. Guilherme Schwan; Dra. Rosemar Ayres dos Santos; Letícia Tamie Oda; Paola Gularte.

Introdução: Me. Guilherme Schwan; Dra. Rosemar Ayres dos Santos

Referencial teórico: Me. Guilherme Schwan; Dra. Rosemar Ayres dos Santos

Análise de dados: Me. Guilherme Schwan; Dra. Rosemar Ayres dos Santos

Discussão dos resultados: Me. Guilherme Schwan; Dra. Rosemar Ayres dos Santos

Conclusão e considerações finais: Me. Guilherme Schwan; Dra. Rosemar Ayres dos Santos

Referências: Me. Guilherme Schwan; Dra. Rosemar Ayres dos Santos

Revisão do manuscrito: Me. Guilherme Schwan; Dra. Rosemar Ayres dos Santos; Luciano Gonçalves Soares.

Aprovação da versão final publicada: Me. Guilherme Schwan; Dra. Rosemar Ayres dos Santos.

\section{CONFLITOS DE INTERESSE}

Os autores declararam não haver nenhum conflito de interesse de ordem pessoal, comercial, acadêmico, político e financeiro referente a este manuscrito.

\section{DISPONIBILIDADE DE DADOS DE PESQUISA}

Os autores declaram que disponibilizarão os dados da pesquisa.

\section{CONSENTIMENTO DE USO DE IMAGEM}

Não se aplica.

\section{APROVAÇÃO DE COMITÊ DE ÉTICA EM PESQUISA \\ Não se aplica.}

\section{COMO CITAR - ABNT}

SCHWAN, Guilherme. SANTOS, Rosemar Ayres dos. Pressupostos Freireanos, CTS e PLACTS no ensino de ciências: aproximações e distanciamentos. REAMEC - Rede Amazônica de Educação em Ciências e Matemática. Cuiabá, v. 9, n.3, e21084, set./dez., 2021. http://dx.doi.org/10.26571/reamec.v9i3.12803.

\section{COMO CITAR - APA}

Schwan, G., Santos, R. A. dos. (2021). Pressupostos Freireanos, CTS e PLACTS no ensino de ciências: aproximações e distanciamentos. REAMEC - Rede Amazônica de Educação em Ciências e Matemática, 9(3), e21084. http://dx.doi.org/10.26571/reamec.v9i3.12803.

\section{LICENÇA DE USO}

Licenciado sob a Licença Creative Commons Attribution-NonCommercial 4.0 International (CC BY-NC 4.0). Esta licença permite compartilhar, copiar, redistribuir o manuscrito em qualquer meio ou formato. Além disso, permite adaptar, remixar, transformar e construir sobre o material, desde que seja atribuído o devido crédito de autoria e publicação inicial neste periódico. 


\section{DIREITOS AUTORAIS}

Os direitos autorais são mantidos pelos autores, os quais concedem à Revista REAMEC - Rede Amazônica de Educação em Ciências e Matemática - os direitos exclusivos de primeira publicação. Os autores não serão remunerados pela publicação de trabalhos neste periódico. Os autores têm autorização para assumir contratos adicionais separadamente, para distribuição não exclusiva da versão do trabalho publicada neste periódico (ex.: publicar em repositório institucional, em site pessoal, publicar uma tradução, ou como capítulo de livro), com reconhecimento de autoria e publicação inicial neste periódico. Os editores da Revista têm o direito de proceder a ajustes textuais e de adequação às normas da publicação.

\section{PUBLISHER}

Universidade Federal de Mato Grosso. Programa de Pós-graduação em Educação em Ciências e Matemática (PPGECEM) da Rede Amazônica de Educação em Ciências e Matemática (REAMEC). Publicação no Portal de Periódicos UFMT. As ideias expressadas neste artigo são de responsabilidade de seus autores, não representando, necessariamente, a opinião dos editores ou da referida universidade.

\section{EDITOR}

\section{Patrícia Rosinke (iD) (9)}

\section{HISTÓRICO}

Submetido: 28 de julho de 2021.

Aprovado: 13 de outubro de 2021.

Publicado: 24 de outubro de 2021. 